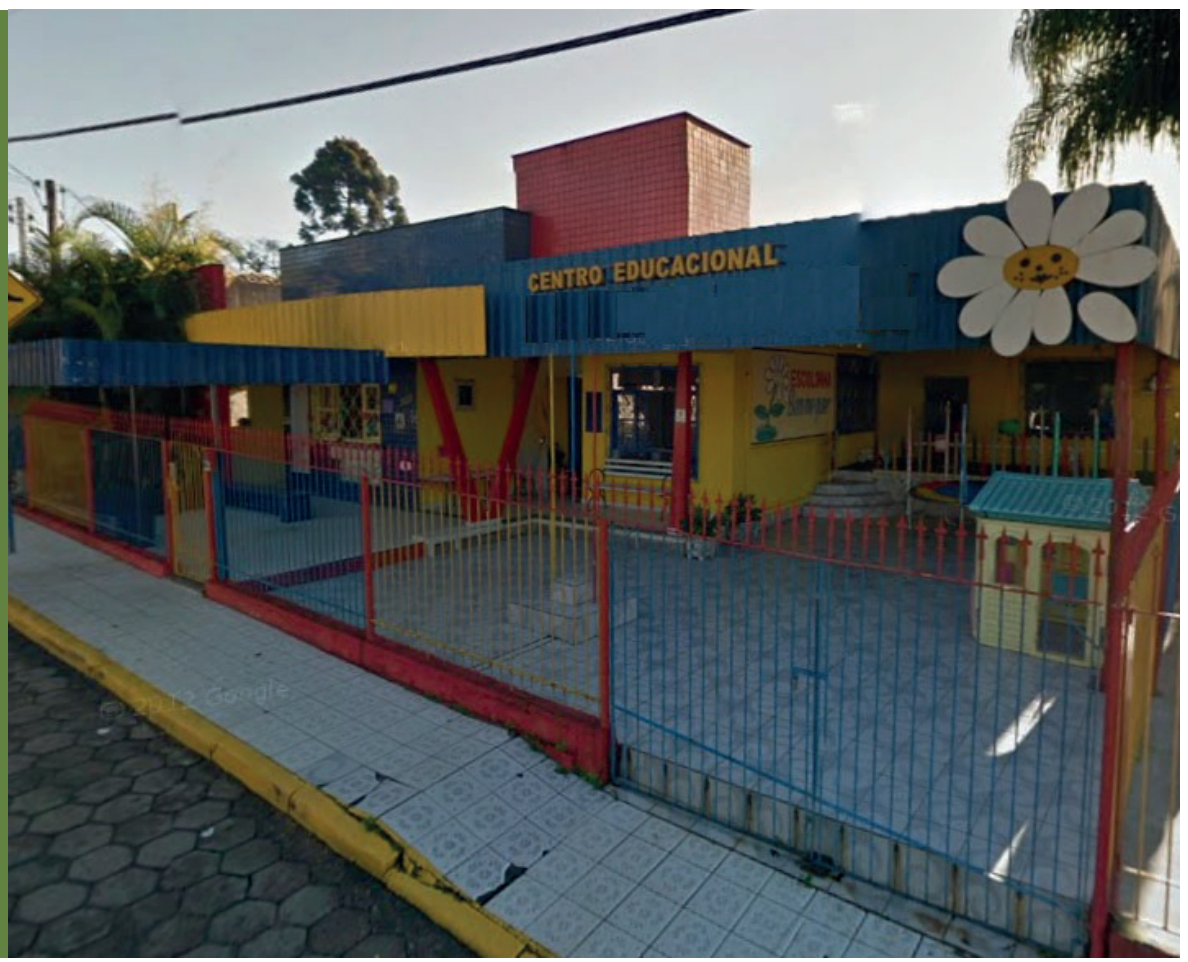

\title{
Curricularização da extensão em curso de nível superior: vivência dos acadêmicos da engenharia civil com escola para autistas
}

\author{
Cleidson Rosa Alves - cleidson.alves@ifsc.edu.br ${ }^{1}$ \\ Graziela Olivo Fermo - graziela.olivo@ifsc.edu.br² \\ Roslene de Almeida Garbelotto - roslene.garbelotto@ifsc.edu.br ${ }^{3}$ \\ Daniel da Silva Comin - daniel.comin@ifsc.edu.br
}

\section{RESUMO}

Os acadêmicos da primeira fase do curso de Engenharia Civil tiveram suas primeiras experiências com atividades de extensão na disciplina de Projeto Integrador 1. A proposta foi buscar instituições públicas que necessitassem de intervenção técnica, na área da construção civil, para sugestão de melhorias nas instalações. A Escola Amigo do Autista (AMA) foi escolhida dentre diversas outras instituições. Os acadêmicos apontaram a necessidade de diversas adequações e sugeriram, com justificativas técnicas, a alteração de local dessa instituição.

\footnotetext{
1 Engenheiro civil, especialista, docente no Núcleo de Construção Civil do IFSC Câmpus Criciúma.

2 Engenheiro civil, mestre, docente no Núcleo de Construção Civil do IFSC Câmpus Criciúma.

3 Engenheiro civil, mestre, docente no Núcleo de Construção Civil do IFSC Câmpus Criciúma

4 Arquiteto e urbanista, mestre, docente no Núcleo de Construção Civil do IFSC Câmpus Criciúma
} 


\section{PALAVRAS-CHAVE}

Intervenção. Extensão. Engenharia Civil.

\section{ABSTRACT}

The academics of the first phase of the Civil Engineering course passed the first experiences with extension activities in the discipline of Integrator Project 1. Students were encouraged to seek institutions that needed technical intervention to be used in the facilities. Autistic-friendly school (AMA) was chosen from several other institutions, where the scholars pointed out the need for various adjustments that suggest the location change of this institution.

\section{KEYWORDS}

Intervention. Extension. Civil Engineering.

\section{Relato de experiência}

\subsection{Justificativa}

As finalidades do Ensino Superior, conforme a Lei de Diretrizes e Bases (LDB) (BRASIL, 1996), são: fomentar a pesquisa e a investigação científica para desenvolvimento da ciência, da tecnologia, da criação e expansão da cultura, visando a compreensão do homem e do meio em que vive. Dessa forma, não basta o desenvolvimento de atividades de ensino-aprendizagem de forma convencional (sala de aula $\mathrm{x}$ professor $\mathrm{x}$ aluno). 0 contexto deve ser ampliado de forma que a investigação científica e a articulação com a comunidade local efetivem a formação do acadêmico. A participação do aluno em atividades que permeiem a tríade ensino, pesquisa e extensão privilegia a formação integral do futuro engenheiro civil, oportunizando a vivência de situações concretas do ambiente de trabalho e a ligação da teoria com a prática.

Desta forma, as diretrizes presentes no Plano Nacional de Educação (PNE), meta 12, e no Regulamento Didático Pedagógico (RDP) do IFSC, aprovado pela Resolução no 41 de 20 de novembro de 2014, indicam a inserção mínima de $10 \%$ da carga horária total da matriz curricular destinada a atividades de extensão, visando o melhor aproveitamento dos alunos. Para seguir essas diretrizes, 0 curso de Engenharia Civil do IFSC Câmpus Criciúma introduziu 395 horas de atividades de extensão diluídas em 18 disciplinas do curso.

A disciplina de Projeto Integrador 1 (PI 1) na primeira fase do curso teve a missão da apresentação das atividades de extensão aos acadêmicos. Foram alocadas $20 \mathrm{~h}$ nesta disciplina de $40 \mathrm{~h}$ para desenvolvimento de um projeto de extensão onde os acadêmicos visitariam instituições públicas na cidade de Criciúma e apresentariam as possíveis intervenções a serem realizadas.

\subsection{Metodologia}

0 objetivo geral da disciplina de PI 1 foi 0 desenvolvimento de um projeto de pesquisa/extensão aplicando conhecimentos da área específica e agregando conhecimentos das unidades curriculares do primeiro semestre. 0 projeto foi proposto na disciplina PI 1 e teve 0 subsídio teórico das disciplinas de Metodologia da Pesquisa (MP) e Desenho Técnico 1 (DT 1). A proposta de integração dos alunos ocorreu por meio do desenvolvimento de trabalhos em grupos, os quais procuraram por instituições públicas na cidade de Criciúma e região que necessitavam de intervenção técnica para melhoria no uso das suas instalações. Os alunos fizeram uma análise crítica por meio de seu conhecimento empírico com a supervisão dos professores especialistas na área. 
Após a escolha das equipes, dez locais foram propostos, apresentados e discutidos em aula, com as justificativas para sequência ou não do desenvolvimento do projeto:

- Praça João Goulart - revitalização de mobiliários;

- Escola Ignácio Stakowski - criação de espaço recreativo;

- Módulo Esportivo - criação de espaço recreativo para terceira idade;

- Praça Santa Bárbara - restruturação;

- Praça Ceará - revitalização da estrutura;

- Escola Tancredo Neves - desenvolvimento de ações sustentáveis;

- Casa Guido - intervenção na estrutura de telhado;

- Escola Pedro da Ré - revitalização de estruturas externas;

- $\quad$ AMA - Escola Amigo do Autista - Alteração de Layout;

- Praça José Celso Colonial - Revitalização de quadra poliesportiva.

Após ampla discussão em sala de aula os professores e os alunos, escolheram o projeto da Escola Amigo do Autista (AMA) para ser objeto de estudo da disciplina.

A AMA é mantenedora da Escola Especial Meu Mundo, que fornece atendimento pedagógico específico a pessoas com Transtorno do Espectro Autista. No ano de 2017 foram atendidos diretamente mais de 100 alunos, com idades dos 3 aos 35 anos, vindos de várias cidades do sul de Santa Catarina. Na escola são prestados vários tipos de atendimento: pedagógico; psicológico; fonológico; fisioterapêutico; terapia ocupacional e assistência social; enfermagem.

Os acadêmicos realizaram visita preliminar nas instalações da escola, divididos em grupos e encorajados a realizarem um levantamento de pontos, tais como: acessibilidade, condições das salas de aula, instalações elétricas, dos espaços de preparação e estocagem de alimentos, equipamentos preventivos de incêndio e conforto térmico dos ambientes.

Após o diagnóstico das condições atuais do local, os resultados foram apresentados para banca multidisciplinar composta pelos professores de PI 1, MP e DT 1, além dos coordenadores do curso e de extensão. Neste momento, a banca deu seu parecer técnico sobre as intervenções propostas para que os resultados pudessem ser conduzidos à direção da AMA.

\subsection{Resultados}

Após a apresentação final, os acadêmicos relataram diversos pontos críticos nas instalações. Alguns desses fatores estavam relacionados às adaptações realizadas pela escola para receber seus alunos.

Para Rodrigues et al (2012), os alunos com Transtornos do Espectro Autista (TEA) surgem como 0 extremo da dificuldade da inclusão, tendo em vista que a ausência da linguagem e 0 alheamento fazem com que 0 trabalho a ser realizado pelos professores ainda esteja distante do esperado e prescrito pedagogicamente. Observam-se uma série de limites para o desenvolvimento de um trabalho efetivo com os alunos com TEA, tais como: a dificuldade individual do aluno e dos professores e a ausência de material e direcionamentos adequados para o trabalho.

Segundo relatos dos professores, os alunos autistas têm dificuldade de locomoção, principalmente em escadas e corredores apertados. Na atual sede da AMA os acadêmicos relataram que o local apresenta três pavimentos, interligados apenas por corredores adaptados, sem espaçamento adequado para a locomoção de grupos de pessoas. A Figura 1 representa 0 layout do pavimento intermediário. 


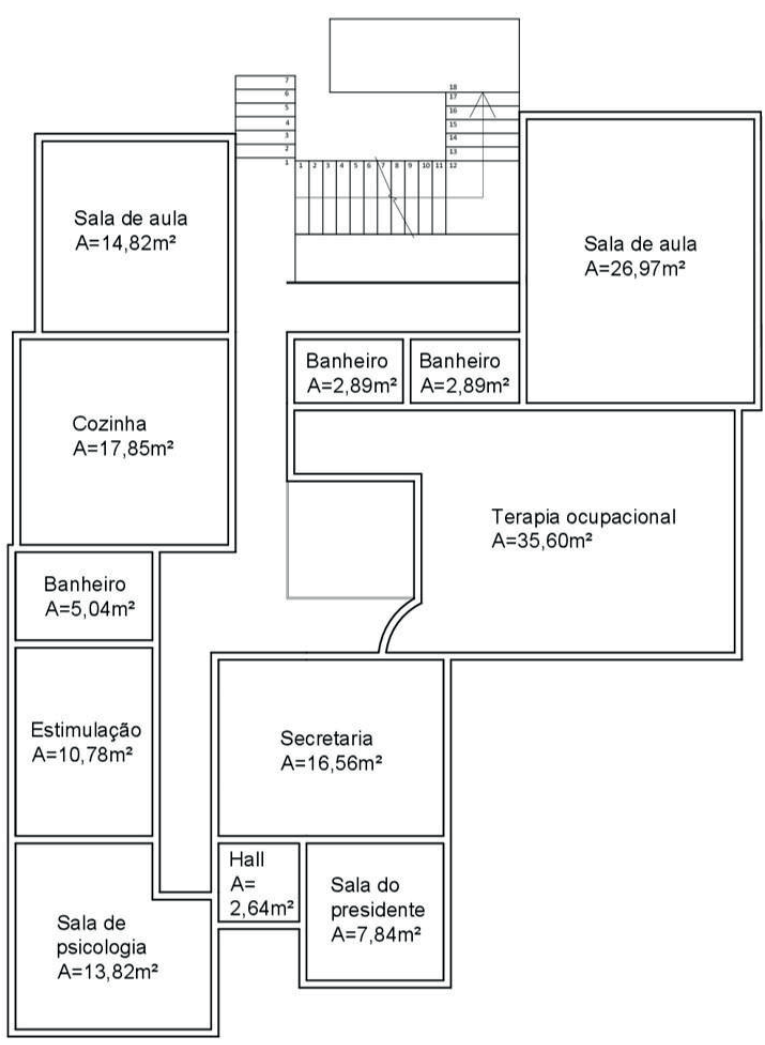

Figura 1: Layout pavimento intermediário AMA.

Fonte: Autores (2018).

Ainda sobre acessibilidade, atualmente a instituição conta com cinco alunos cadeirantes, que se locomovem apenas pelo pavimento térreo, deixando de utilizar salas importantes como a de fisioterapia, que fica no pavimento intermediário.

As portas das salas têm vão de $70 \mathrm{~cm}$ e, de acordo com a Associação Brasileira de Normas Técnicas (ABNT), em especial a NBR 9050/2015, um vão suficiente para um cadeirante passar deve ser de $90 \mathrm{~cm}$

0 pavimento térreo conta com apenas um banheiro (Figura 2), não adaptado para pessoas com necessidades especiais, dificultando muito o uso pelos alunos. Ainda nesse pavimento, há desníveis em forma de degraus (Figura 3) não oferecendo segurança ao trânsito dos alunos que frequentam a AMA.
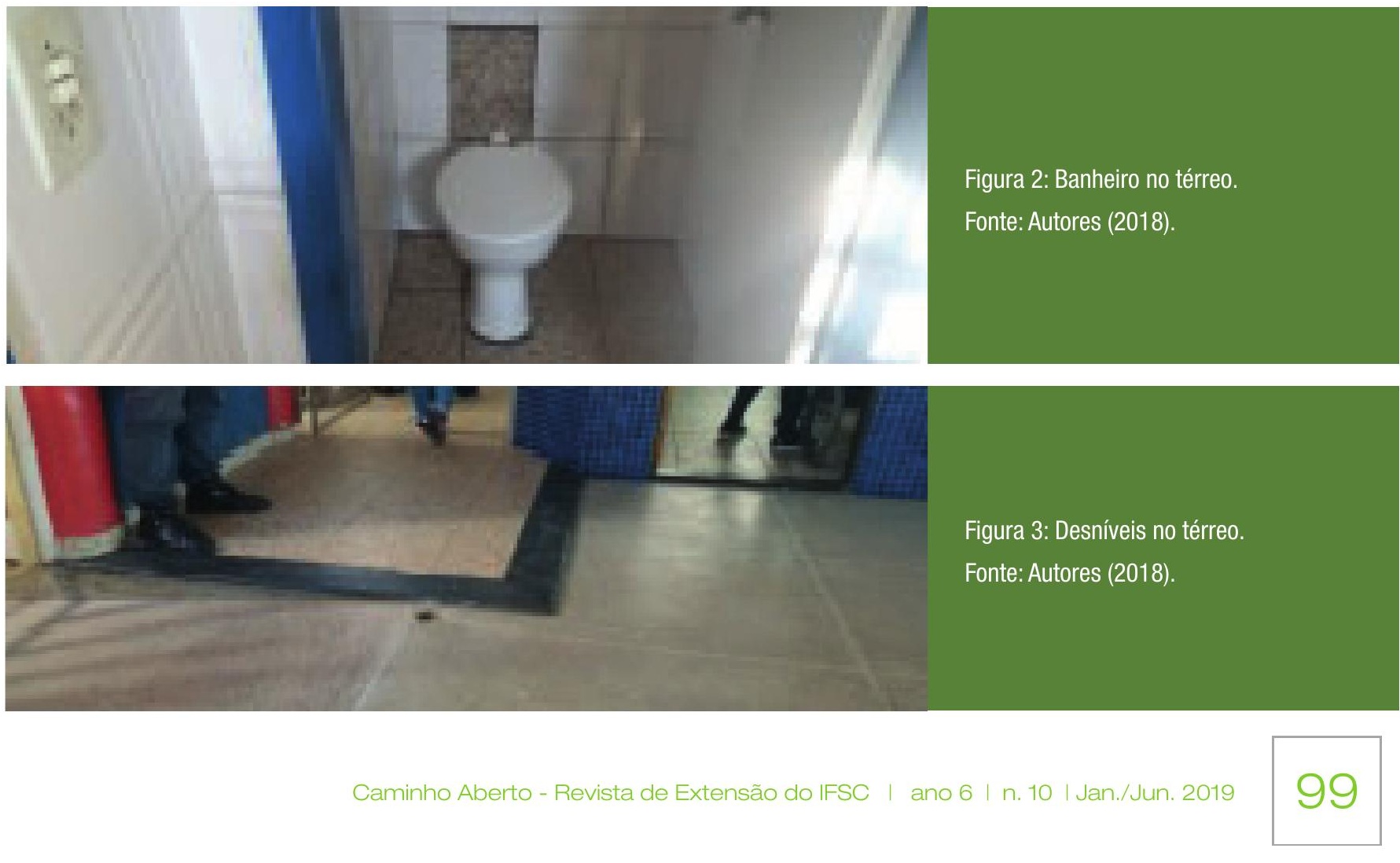
Outro ponto relatado pelos alunos está associado às condições de segurança da instituição, tais como: problemas nas instalações elétricas; extintores estão em locais de difícil acesso; cozinha com ventilação inadequada; instalação de GLP (Gás Liquefeito de Petróleo) no interior da cozinha.

\subsection{Considerações Finais}

A atividade de extensão realizada oportunizou aos acadêmicos da primeira fase do curso de Engenharia Civil a vivência com situações concretas do ambiente de trabalho, articulando teoria e prática ao ensino.

A busca por instituições públicas com necessidade de intervenção, a análise dos problemas observados e 0 debate em grupo permitiu a escolha da instituição a ser contemplada pelo projeto: AMA.

Visitas técnicas à instituição, auxiliadas pelos professores da disciplina, resultaram na elaboração de um diagnóstico sobre a edificação, entregue à direção da instituição. Questões como acessibilidade, condições de segurança, conforto térmico e manutenção foram abordadas no documento. Em face das condições apresentadas, constatou-se que as adequações necessárias são inúmeras e com soluções relativamente complexas, considerando que a edificação não foi projetada para tal finalidade. Deste modo, diante da relação custo/benefício dessas adequações, bem como considerando que o espaço utilizado é locado, apontou-se como melhor alternativa que a instituição mude de local, pois o mesmo não oferece segurança aos envolvidos nas atividades diárias.

Os resultados alcançados somente foram possíveis com alunos da primeira fase do curso pela indissociabilidade entre ensino, pesquisa e extensão. Os professores deram o suporte necessário em sala de aula e orientaram os alunos no levantamento de dados. Os alunos, com a orientação dos professores, buscaram um problema real na comunidade local e por meio de estudos teóricos e de outros referenciais puderam diagnosticar e propor os resultados apresentados.

Para os acadêmicos a experiência foi enriquecedora, permitindo a introdução ao mundo do trabalho de um engenheiro civil. Tiveram que trabalhar com os colegas, procurar as instituições que desempenharam uma situação de cliente, ouvir e sentir o apoio dos professores com a visão de profissional, buscar argumentos nas normas para fundamentar a solução apresentada. Todos envolvidos saíram ganhando: os acadêmicos, os professores e a AMA.

\section{Referências}

ASSOCIAÇÃO BRASILEIRA DE NORMAS TÉCNICAS. NBR 9050: Acessibilidade a edificações, mobiliário, espaços e equipamentos urbanos. Rio de Janeiro, 2015a.

BRASIL. IFSC. Regulamento didático-pedagógico. Florianópolis. 2014.

RODRIGUES, Isabel de Barros; MOREIRA, Luiz Eduardo de V.; LERNER, Rogério. Análise institucional do discurso de professores de alunos diagnosticados como autistas em inclusão escolar. Psicologia, teoria e prática. São Paulo , v. 14, n. 1, abr. 2012.

BRASIL. Lei de Diretrizes e Bases da Educação Nacional. Brasília. 1996.

BRASIL. Plano Nacional de Educação. Brasília. 2001. 